\title{
Endometriosis Pathogenesis and Management
}

\author{
Shawky ZA Badawy* \\ Department of Obstetrics and Gynecology, Reproductive Endocrinology, Pathology, Upstate Medical University Syracuse, USA \\ *Corresponding author: Shawky ZA Badawy, Department of Obstetrics and Gynecology, Reproductive Endocrinology, \\ Pathology, Upstate Medical University Syracuse, New York, USA
}

\begin{tabular}{|c|c|}
\hline ARTICLE INFO & ABSTRACT \\
\hline Received: 豐 June 28, 2019 & Citation: Shawky ZA Badawy. Endometriosis Pathogenesis and Management. Biomed J \\
\hline Published: 㸷 July 05, 2019 & Sci \& Tech Res 19(3)-2019. BJSTR. MS.ID.003299. \\
\hline
\end{tabular}

\section{Introduction}

Endometriosis has been described over 300 years ago [1-3]. It is a major cause of pain and infertility in $35-50 \%$ of women and chronic pelvic pain in 6-10\% of women. It is a major cause of hospitalization and hysterectomy, with annual cost of 1.8 billion dollars in 2009 in Alberta and Quebec, Canada [4], 1.5 billion dollars in Germany, and 20 billion dollars in the United States [5]. Endometriosis is an estrogen dependent condition. On the other hand, this disease leads to defective response of Eutopic endometrium to progesterone and therefore implantation is difficult to occur thus leading to infertility or pregnancy loss. In addition, nerve fibers have been demonstrated in Eutopic endometrium of patients with endometriosis [6].

Infertility due to pelvic endometriosis may be caused by several factors. Ovulatory dysfunction may result from the high concentrations of prostoglandins and cytokines in the peritoneal fluid in these patients [7]. Prostaglandins also may lead to tubal dysfunction that will interfere with the pickup of the oocyte from the ovary, and also the motion of the sperm towards the oocyte with the result of failure of fertilization to take place. Furthermore, the endometrium of these patients has been shown to have aromatase that leads to high estradiol concentration and that might lead to defective response to progesterone, and the end result will be failure of implantation [8].

\section{Historical Aspects of Endometriosis}

The first reference to endometriosis associated symptoms are found in the Ebers Papyrus (Tebas, Egypt, 500 BC) in which treatment for painful disorder of menstruation is described. In the 18th Century, scientists from England, Germany, Holland, and Scotland described endometriosis in autopsy studies [9]. Rokitansky (mid part of 19th Century-1885), suggested the presence of endometrial glands and stroma in ovarian and uterine neoplasia [10]. Cullen
(1919) [11]: Was the first scientist to demonstrate histologically endometrial structures in the peritoneum of patients and called this process as adenomyoma of the peritoneum or adenomysis externa. Russel [12]: Published a report in 1899 of an ovaries containing uterine mucosa. Sampson (1927) [13]: The first to describe the menstrual reflux theory for the development of endometriosis. He also described the various types of the disease including chocolate cysts, and deep infiltrating disease in the pelvis.

Pathogenesis of Endometriosis - Criteria of Eutopic Endometrium as Precursor for Endometriosis [14-17]

a) Macrophages are increased with increased interleukins and prostaglandins.

b) Apoptosis of endometrial cells is reduced.

c) Increased integrins that leads to proliferation of endometrial cells.

d) Increased various growth factors leading to increase angiogenesis.

e) Aromatase in these cells increases estrogen production which leads to increased proliferation of these cells.

f) Increase metalloproteinases promotes invasion of endometrial cells and development of endometriosis.

g) Increase in Estrogen Receptor B in endometriosis is important in establishment and progression of the disease.

\section{Theories for development of Endometriosis}

A. Retrograde menstrual fluid through Fallopian tubes

B. Stem cells from basal endometrium, or bone marrow 
C. Displaced embryonic epithelial remnants along the underdeveloped Mullerian system, can lead to endometriosis as reported in patients with Mullerian Agenesis (MRKH)

D. Coelomic Metaplasia Theory

E. Genetic predisposition

F. Ovarian chocolate cyst

Inversion of ovarian cortex with the endometriosis implant.

i. or- Secondary involvement of functional ovarian cyst.

ii. or - Metaplasia of Coelomic epithelium on the ovary.

\section{Diagnosis of Endometriosis}

Usually patients present with history of severe dysmenorrhea, pelvic pain, and dysparunia. If there is a bowel involvement, patient then will have constipation, diarrhea, and rectal bleeding. If there is bladder involvement, the patient will have hematuria. The pelvic examination will demonstrate pelvic pain, thickened and indurated utero sacral ligaments, and enlarged ovaries if there are endometriomas. Pelvic sonogram will aid in the diagnosis demonstrating masses or cysts. MRI of abdomen and pelvis may be ordered to evaluate abdominal or intestinal masses.

\section{Ultrasound Based Endometriosis Staging (UBESS)}

a) Assessment of uterus and adnexa

b) Tenderness guided assessment

c) Assessment of pouch of Douglas status, ovarian and organ mobility

d) Assessment of none bowel deep endometriosis of anterior, lateral, and posterior pelvic compartments

e) Assessment of anterior wall of rectum and sigmoid.

This system has been used in Australia and New Zealand [18].

The next step in the diagnosis is laparoscopy [19]. This helps to define the disease and its location according to its morphologic criteria which includes vesicular forms, dark pigmented areas, or chocolate cysts in the ovaries. The vesicular form and pigmented areas can be treated with laser or using electro cautery to ablate the disease. In cases of chocolate cysts, the endometrioma is surgically excised followed by reconstruction of the ovary.

\section{Medical Treatment of Endometriosis}

Medical treatment of endometriosis is applied to early stages of the disease or recurrence after surgical medical treatment. Usually the treatment is for a period of six months. Various medications are used including birth control pills, Danazol, Medroxyprogesterone and GnRH agonist or antagonist [20].

\section{Birth Control Pills}

Use of steroidal oral contraceptives in patients with endometriosis alleviates severe dysmenorrhea in these patients. There are no data to support any effect on the reduction of the size of the lesions.

\section{Danazol}

This is a synthetic steroid derivative of 17 alpha-ethinyl testosterone. It inhibits the secretion of FSH and $\mathrm{LH}$, and leads to inhibition of ovarian function. The end result is pseudomenopause, and hypoestrogen status. This leads to suppression of endometriosis and its regression in about $80 \%$ of the patients. Following discontinuation of the treatment, the pregnancy rate is about $70 \%$. The recurrence rate after 24 months follow up was reported to be $29 \%$.

\section{Gonadotropin Releasing Hormone Agonist}

Its administration leads to suppression of gonadotropins through inhibition of GnRH receptors in pituitary. This will lead to hypoestrogenism and the end result is suppression of endometriosis. This also leads to reduction in dysmenorrhea.

\section{The use of gonadotropin releasing hormone antagonist}

All the studies show that the use of GnRH antagonist for pain related to endometriosis, have shown marked improvement. The medication is well tolerated. It is also an oral medication. Laproscopic studies showed regression of endometriosis.

\section{Antiangiogenic Factors}

In a study to evaluate cabergoline effect on endometrioma, as compared to control groups given GnRH agonist $3.75 \mathrm{mg}$ subsequently one time. Patients were evaluated by base line sonogram and 3 months after the treatment. The results showed significant decrease in size of endometrioma with the use of Cabergoline [21]. The use of Quinagolide for treatment of endometriosis induced in a rat model. The results showed significant decrease in interleukin 6 and vascular endothetrial growth factor in peritoneal fluid samples after Quinagolide treatment as compared to levels before treatment. In addition, tissue samples showed significant reduction of glandular and stromal tissue after the treatment. The use of Lovostatin added to endometrial in vitro culture, showed inhibition of cell proliferation and angeogensis. All these agents are still being under evaluation and certainly will add new lines of medical treatment for endometriosis.

\section{Surgical Management}

This is usually done by laparoscopy and or laparotomy. The lesions are either excised, or fulgrated using bipolar cautery; or vaporized using laser [22]. Recently a study in experimental animals showed the beneficial effect of platelet rich plasma, and 
fibrin sealant on bowel wound healing after shaving endometriosis lesions experimentally induced. The results showed that these agents are safe and associated with improved tissue healing after shaving endometriosis from colon wall.

\section{Extrapelvic Types of Endometriosis}

\section{Thoracic Endometriosis [23,24]}

This includes these categories

\section{a. Catamenial Pneumothorax \\ b. Catamenial Hemothorax \\ c. Catamenial hemoptysis}

These result from the presence of endometrial glands and stroma in the lungs and pleura. Endometrial tissue may have migrated from the abdomen, through defects in the diaphragm and resided in the chest. Another possibility is hematogeneous and/or lymphatic spread. The diagnosis to confirm the disease is facilitated by biopsies from pleura in cases of catamenial pleural effusion or catamenial hemothroax. In cases of catamenial hemoptysis, the use of bronchoscopy and lung biopsy will help to establish the diagnosis. In addition to the surgical treatment, the use of medical treatment may be helpful. This is accomplished with the use of GnRH agonist, or Danozol. If fertility is not an issue, then the patient will benefit from total abdominal hysterectomy and bilateral salpingo oophorectomy.

\section{Intestinal Endometriosis}

This is the most common extrapelvic location of endometriosis. It commonly affects the rectosigmoid part of the bowel. It could be superficial disease, but sometimes it affects the whole thickness of the bowel wall. The symptoms will vary according to the degree of bowel involvement. The patient will complain of pelvic pain, or abdominal pain. In addition, the symptoms may be diarrhea, constipation, and/or rectal bleeding. Radiological studies including CT scan, MRI of the abdomen will show the location of the lesion. In addition, Barium enema and Colonoscopy will be confirmatory. Small intestines may be affected with endometriosis, but it is usually less common. The treatment of bowel endometriosis is surgical excision, and bowel anastomosis. The incidence of bowel endometriosis is $12 \%$ in women with endometriosis.

\section{References}

1. Knapp VJ (1999) How old is endometriosis? Late $17^{\text {th }}$ and 18 th Century European descriptions of the disease. Fertil Steril 72(1): 10-14.

2. Liselotte Mettler, Dietmar Schmidt, Pter Maher (2016) The impact of endometriosis on health of women 2016. 2016: 1747280.

3. Levy AR, Osenekokm, Lozano Ortega G, Sambrook R, Jeddi M, et al. (2011) Economic burden of surgically confirmed endometriosis in Canada. J Obstetrical Gynecology 33 (8): 830- 837.

4. Bansari G Patel, Martin Rudnicki, Jie Yu, Yimin Schu, Robert N (2017) Taylor: Acta Obstetrics et Gynocologica Scandinavica 96: 623-632.
5. Badawy SZ, Cuenca V, Marshall L (1987) Peritoneal fluid prostaglandins in patients with endometriosis. Contrib Gynecological Obstetrics 16: 6065.

6. Luis S Noble, Evan R Simpson, Alan Johns, Serdar E Bulun (1996) Aromatase expression in Endometriosis. J Clin Endocrinology Metab 81(1): 174-179.

7. Benagiano G, Brosens I (1991) The history of endometriosis: Identifying the disease. Hum Reprod 6(7): 963-968.

8. Benagiano G, Brosens I (2009) Who identified endometriosis? Fertil Steril 92: 1536-1543.

9. Cullen T (1896) Adenomyoma of the round ligament. Johns Hopkins Hospital Bull 7: 112-113.

10. Russell W (1899) Aberrant portions of the Mullerian duct found in an ovary. Ovarian cysts of Mullerian origin. Bull John Hopkins Hosp 10(8).

11. Sampson JA (1925) Heterotopic or misplaced endometrial tissue. Journal of Obstetrics and Gynecology 10: 449-664.

12. Bruner-Tran KL, Eisenberg E, Yeaman GR, Anderson TA, McBean J, et al. (2002) Steroid and cytokine regulation of matrix metalloproteinase expression in Endometriosis and the establishment of experimental endometriosis in nude mice. J Clin Endocrinol Metab 87: 4782-4791.

13. Shifren JL, Tseng JF, Zalondek CJ, Ryan IP, Meng YG, et al. (1996) Ovarian steroid regulation of vascular endothelial growth factor in the human endemetrium: Implications for angiogenesis during the menstrual cycle and in the pathogenesis of endometriosis. J Clin Endocrinol Metab 81: 312-318.

14. McLaren J, Prentice A, Charnock-Jones DS, Smith SK (1996) Vascualr Endothelial growth factor (VEGF) Concentrations are elevated in peritoneal fluid of women with endometriosis. Hum Reprod 11: 220223.

15. Tompsett J, Leonardi M, Gerges B, Lu C, Reid S, et al. (2019) Ultrasound based endometriosis staging system: validation study to predict complexity of laparoscopic surgery. J Minim Invasive Gynecol 26(3): 477-483.

16. Erica Schipper, Camran Nezhat (2012) Video assisted laparoscopy for the detection and diagnosis of endometriosis: Safety, reliability, and invasiveness. Int J Women's Health 4: 383-393.

17. (2010) Practice Bulletin No. 114: Management of endometriosis. Obstet Gynecol 116(1): 223-236.

18. Ferrero S, Ragni N, Remorgida V (2006) Antiangiogenic therapies in Endometriosis. Br J Pharmacol 149(2): 133-135.

19. Visouli AN, Zarogoulidis K, Kougioumtzi I, Huang H, Li Q et al. (2014) Catamenial Pneumothorax. J Thorac Dis 6: 5448-5460.

20. Foster DC, Stern JL, Buscema J, Rock JA, Woodruff JD (1981) Pleural and parynchemal pulmonary endometriosis. Obstet Gynecol 58: 552-556.

21. Wood DJ, Krishnan K, Ward MJ (1993) Catramenial hemogstysis a rare cause. Thorax 48: 1048-1049.

22. Remorgida V, Ferrero S, Fulchori E, Ragni N, Martin DC (2007) Bowel endometriosis: presentation, diagnosis, and treatment. Obstet Gyncolol Surg 62(7): 461-470.

23. Gustofson RL, Kim N, Liu S, Stratton P (2006) Endometriosis and the appendix: A case series and comprehensive review of the literature. Fertil Steril 86(2): 298-303.

24. Faccioli N, Foti G, Manfredi R, Mainardi P, Spoto E, et al. (2010) Evaluation of colonic involvement in endometriosis: Double- contract barium enema vs. magnetic resonance imaging. Abdom Imaging 35(4): 414-421. 


\section{ISSN: 2574-1241}

DOI: 10.26717/BJSTR.2019.19.003299

Shawky ZA Badawy. Biomed J Sci \& Tech Res

(C) This work is licensed under Creative

Submission Link: https://biomedres.us/submit-manuscript.php

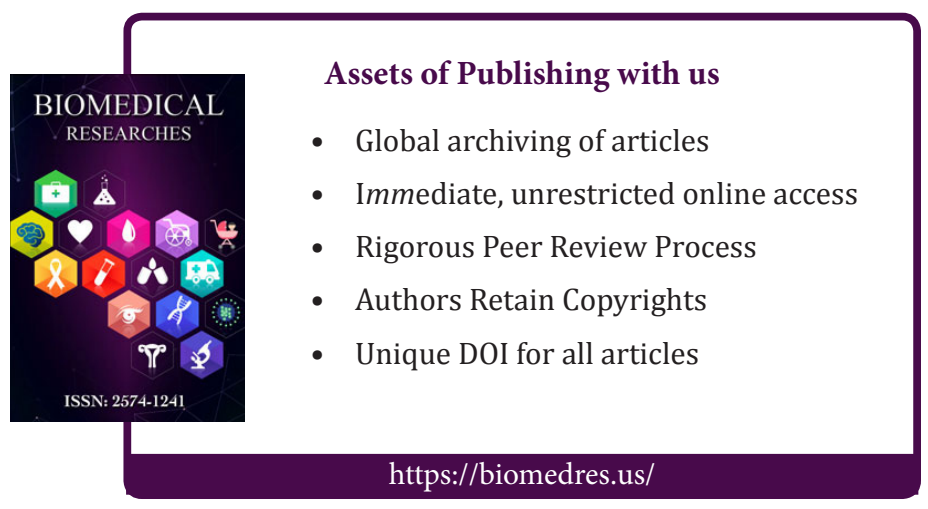

